\title{
Monetary valuation of illnesses in Costa Rica: a subjective well-being approach
}

\author{
Mariano Rojas ${ }^{1}$
}

Suggested citation Rojas M. Monetary valuation of illnesses in Costa Rica: a subjective well-being approach. Rev Panam Salud Publica. 2009;26(3):255-65.

\begin{abstract}
Objective. This report aims to 1) explain and illustrate the use of the subjective well-being (SWB) approach as an alternative health-valuation methodology by estimating the monetary value of five general categories of illness in Costa Rica, and 2) foster comparative research on the advantages and limitations of alternative approaches to health valuation.

Method. Use of the SWB valuation approach to measure the monetary value of illness (MVI), based on empirical data from a representative survey in Costa Rica carried out in 2004. The MVI is defined as the estimated percentage of monthly income that would be required to compensate for the loss in life satisfaction (LS) - a primary SWB conception - that is expected to occur with the onset of illness. The five general categories of illnesses studied were cancer, cardiovascular disease, thyroid disease, arthritis, and infectious disease.

Results. There was wide disparity in the monetary values of the different illnesses. Some illnesses had relatively high monetary value compared to persons' mean income, indicating the high value of good health and of programs that aim to prevent the emergence of illnesses or abate their negative impact on people's well-being.

Conclusions. The SWB valuation approach can be used to estimate illnesses' monetary value and thus can contribute to the design of health policies related to resource allocation and compensation, and revenue-generating schemes.
\end{abstract}

Key words Health policy; cost of illness; personal satisfaction; happiness; Costa Rica.

Maintaining good health is a primary personal and social concern worldwide, as it is widely recognized that illness affects well-being. However, this impact is not equal for all illnesses. Accurate valuations of specific illnesses' well-being impact (WBI) can improve efficiency in resource allocation and the design of revenue-generating and compensation

\footnotetext{
Facultad Latinoamericana de Ciencias Sociales, Sede México and Universidad Popular Autónoma del Estado de Puebla, Mexico. Send correspondence and reprint requests to: Mariano Rojas, Professor of Economics, UPAEP, 21 sur 1103, Colonia Santiago Puebla, PUE 72160, Mexico; telephone: +01 52 (222) 229 9400; e-mail: mariano.rojas.h@ gmail.com
}

schemes. These types of estimates can also help policy-makers weigh the wellbeing outcome of social development (e.g., disease prevention and health promotion) versus economic growth. For example, WBI assessments measuring the effect of lower disease prevalence versus increased income could be used to identify policies that contribute the most to societal well-being, and thus support decision-making on trade-offs between physical investment and social policies and programs.

Based on the emerging literature on subjective (self-assessed) well-being, this study uses a relatively new approach to estimate the monetary value of an illness
$(1,2)$ known as the subjective well-being (SWB) valuation approach-a promising alternative to better-known policymaking methodologies such as contingent valuation, standard gambles, time trade-offs, and hedonic pricing (3-6).

The empirical research for the study was based on data from Costa Rica, a relatively egalitarian middle-income country with high socioeconomic indicators. It focused on one component of SWB: the conception of life satisfaction (LS). The effect of five general categories of illness (cancer, cardiovascular disease, thyroid disease, arthritis, and infectious disease) on LS was analyzed using a domains-oflife approach (i.e., estimating the impact 
of various illnesses in various areas of peoples' lives in order to estimate total impact on LS). The research also estimated the WBI of income-and the monetary compensation required to keep satisfaction with life at a constant level despite the onset of illness. Based on these estimates, the monetary valuations of the five types of illnesses were calculated. There was a wide disparity in the monetary value of the different illnesses, and some were relatively high compared to persons' income. These types of general results, along with the specific valuation estimates, could help policymakers estimate the WBI of their policies and programs.

\section{MATERIALS AND METHODS}

\section{SWB approach}

Satisfaction and happiness are both commonly accepted conceptions of SWB $(7-10) .^{2}$ However, satisfaction is assumed to be less volatile and more cognitive-oriented than happiness (1315) and therefore closer to the traditional conception of overall well-being as "having a happy life" (based on personal judgment) (16). The SWB approach uses life satisfaction or LS as the primary indicator of well-being and requires that it be measured based only on a person's responses to direct questions (i.e., it does not allow for speculation based on a person's possessions, facial expressions, or extrinsic behavior) (17).

Use with domains-of-life approach. The domains-of-life approach asserts persons' lives can be viewed as a general construct of various specific, concrete areas, and defines LS as the collective result of different levels of satisfaction across these life domains (18-20). ${ }^{3}$

The enumeration and demarcation of life domains is arbitrary and thus can range from a small number to an almost infinite recount of human activities and spheres of being. Therefore, the way in which human life is divided into specific partitions in a particular study depends

\footnotetext{
2 There is also a "psychological-health" conception of SWB (based on multidimensional measures) (11), and a hedonic conception (12).

3 Cummins RA. A model for the measurement of subjective well-being through domains [draft]. Melbourne (Australia): School of Psychology, Deakin University; 2003.
}

on the research objectives. However, as explained by the current author in a past study (21), all partitioning of life domains must satisfy three criteria:

1. Parsimony. The number of domains must be manageable, and each domain should refer to a clearly separable sphere of being.

2. Meaning. The life domains delimited by the researcher must correspond to how people view their lives.

3. Usefulness. The delimitation of the life domains must contribute to the understanding of the subject of study.

A meta-study of the SWB literature reveals a variety of different domains-oflife partitions. For example, Cummins (18) advocates the use of a seven-domain partition (material well-being, health, productivity, intimacy, safety, community, and emotional well-being), whereas Argyle (11) suggests domains such as money, health, work and employment, social relationships, leisure, housing, and education; Flanagan (22) partitions human life into 15 components; and Headey and Wearing (23) use leisure, marriage, work, standard of living, friendships, sex life, and health. While some research has investigated satisfaction in all domains of life (24-27), most SWB studies focus on a few or just one, such as satisfaction with one's occupation (job, domestic work, studies) $(28,29)$ or health $(30,31)$.

Recently, van Praag et al. studied the relationship between satisfaction in different domains of life (health, financial situation, occupation, housing, leisure, and environment) and satisfaction with life as a whole, and concluded that "satisfaction with life as a whole can be seen as an aggregate concept, which can be unfolded into its domain components" (32: 3).

Application in health valuation. The SWB approach is based on the premise that LS is explained by persons' satisfaction across all life domains and can therefore be affected by changes in satisfaction in any of them, as shown in Equation 1:

$$
L S=f\left(D S^{1}, \ldots, D S^{n}\right)
$$

where $L S$ refers to life satisfaction, and $D S^{1}, \ldots D S^{n}$ equals $D S^{k}$ (satisfaction in domain $k$, with $k=1, \ldots, n$ ).
In a second stage of research, the domains-of-life approach is used to calculate the effect of changes in income and the onset of illness on satisfaction in various areas of life (assuming the WBI of both factors may vary across the different realms), as shown in Equation 2:

$$
D S^{k}=g^{k}\left(Y, I_{h^{\prime}} Z\right)
$$

where $Y$ refers to income, $I$ refers to the presence of illness $h$ (with $h=1, \ldots, 5$ ), Z refers to a vector of socio-demographic variables, $k$ refers to the specific life domain under consideration, and $g^{k}$ denotes the specific relationship (set of parameters) between satisfaction in domain $k$ and the set of explanatory variables.

Based on Equations 1 and 2, the following relationships are specified:

$L S=j\left(D S_{1}\left(Y, I_{h^{\prime}} Z\right), \ldots, D S_{n}\left(Y, I_{h^{\prime}} Z\right)\right)[3]$

Finally, the monetary value of illness $h$ is calculated as the change in income that is required to hold a person's satisfaction with life constant with the onset of illness (33). Total differentiation (d) of LS in Equation 3, with respect to $Y$ and $I_{h^{\prime}}$ and satisfying the condition for LS to remain constant, yields the general formula for calculating the monetary value of illness $h\left(M V I_{h}\right)$ shown in Equation 4:

$$
M V I_{h}=\left.\frac{d Y}{d I_{h}}\right|_{d L S=0}=-\frac{\sum_{k=1}^{n} \frac{\partial L S}{\partial D S^{k}} \frac{\partial D S^{k}}{\partial Y}}{\sum_{k=1}^{n} \frac{\partial L S}{\partial D S^{k}} \frac{\partial D S^{k}}{\partial I_{h}}}
$$

Based on this general formula, and Equations 1 and 2, the specific formula ultimately used to calculate $M V I_{h}$ is derived.

Advantages. The SWB valuation approach has several advantages compared to more traditional valuation measures, most of which are based on willingness to pay (WTP) methodology $(3,4,34)$. For example, while both the SWB and WTP approaches require a survey subject to self-assess his/her current well-being (or "utility"), only the WTP approach requires him/her to accurately predict the WBI of a particular illness, even if they have never experienced it. In addition, the WTP approach requires survey subjects to accurately calculate the WBI of an 
increase in income (even those who have never received that level of income).

As described in the SWB literature, subjects tend to overestimate the WBI of additional income due to a lack of consideration of the effects of habituation and changing aspirations $(35,36)$, which can, in turn, result in an underestimation of the increase in income required to compensate for the effects of illness. In addition, subjects may not accurately predict the WBI of an illness, especially if they have never experienced the illness and are therefore not aware of its potential effects on their life and the lives of their family. In addition, due to cognitive limitations, survey subjects may experience difficulty in processing the large amounts of information required for WTP valuations, which may lead to response errors-a frequently cited drawback of WTP valuation methods that require probability handling, such as standard gambling methods. The SWB valuation requires less information from survey subjects and thus simpler information processing, implying a substantial reduction in appraisal errors.

\section{The survey}

The University of Costa Rica (UCR) conducts yearly surveys each July to gather information on topics considered important for public policy in Costa Rica. These nationally representative surveys are widely recognized due to UCR's survey experience and knowledge base. The data source for the current study was the 2004 survey, which included a battery of new questions related to SWB and health. About 1000 questionnaires were properly completed, providing information on the following variables:

- Socio-demographic indicators (age, gender, and education). The average age of survey respondents was 37 years (with about $25 \%$ of the sample younger than 24 and 9\% older than $65)$, and $50.5 \%$ were women. The average level of education fell between secondary school and high school (with $29 \%$ reporting their highest level of schooling as primary education, and $15 \%$ reporting a university degree).

- Economic indicators (current monthly household income). Respondents' average monthly household income was approximately 250000 Costa Rican colones (about US\$ 540). About $20 \%$ of those surveyed reported a household income below US\$200, and 8 percent reported an income above US\$ 1000 .

- Level of LS. In response to one question ("Taking everything in your life into consideration, how satisfied are you with your life?"), survey subjects were asked to select one of seven ordinal responses ("extremely unsatisfied," "very unsatisfied," "unsatisfied," "neither satisfied nor unsatisfied," "satisfied," "very satisfied," and "extremely satisfied") to describe their satisfaction with life. In the analysis, the LS variable was treated as a cardinal number ranging from 1 and 7 , with 1 corresponding to the lowest level of satisfaction ("extremely unsatisfied") and 7 corresponding to the highest ("very satisfied"). 4

- Satisfaction in various concrete areas of life. Respondents were asked about their level of satisfaction in the following seven domains of life:

1. Health

2. Economic

3. Occupation (main activity, e.g., job, domestic work, studies)

4. Family (relationships with spouse and children)

5. Friendship (relationships with friends and neighbors)

6. Personal (availability of time to pursue personal hobbies and interests as well as recreational and personaldevelopment activities)

7. Community services (e.g., trash collection, public transport, road conditions, public lighting, neighborhood safety).

- Health indicators. Survey respondents were asked if they had been sick from any of the following five general categories of illness in the last six months: cancer, cardiovascular disease, thyroid disease, arthritis, and infectious diseases. Variables were treated as dichotomous (with a value of 1 representing those who had been sick), and interaction variables were constructed

\footnotetext{
4 The author found no substantial differences in results when LS was treated as an ordinal number versus a cardinal variable. This concurred with previous findings by Ferrer-i-Carbonell and Frijters (37), who concluded that "assuming cardinality or ordinality of the answers to general satisfaction questions is relatively unimportant to results."
}

for cases that reported being sick from two or more illnesses simultaneously. ${ }^{5}$

\section{RESULTS}

\section{Incidence of illness}

Respondents reported a low incidence of cancer and thyroid disease (with only $1.5 \%$ of those surveyed reporting cancer, and only $3.8 \%$ reporting thyroid disease $)^{6}$ and a relatively high incidence of cardiovascular and infectious disease (10.2 and $12.7 \%$, respectively). Incidence of arthritis was moderate (6.5\%).

Some people reported being sick from more than one of the five illnesses, whereas 715 people (out of 1000 ) said they had not suffered from any illness during the past six months. Out of the entire cohort, 218 persons reported being sick from just one of the illnesses under study; 40 persons said they had been sick from two illnesses; 13 persons reported three illnesses; and two persons reported four illnesses. Although cases experiencing two or more illnesses were not studied per se, interaction variables were constructed to represent this group in order to obtain better estimates for the illness coefficients. ${ }^{7}$

\section{LS and domain satisfaction}

Most survey respondents reported being either "satisfied" or "very satisfied" with their lives (with 36.6 percent reporting the former and 32.5 percent the

\footnotetext{
5 It should be noted that the research data on the illnesses per se are limited not only with respect to the number of illnesses studied but also because the survey did not distinguish between those who were sick in the last six months but were well at the time of the study and those who were sick in the last six months and were still ill at the time of the study. Furthermore, the survey did not inquire about the severity of the illness (which could range from non-life-threatening to treatable/mild, life-threatening, nontreatable, and debilitating). Due to these limitations in the health indicators, the study results should be considered crude data.

6 This low level of incidence increases the standard error of the estimated coefficients and influences the level of significance of the Student's $t$-test in regression analysis.

7 To maintain parsimony in the number of variables in the multiple regression analyses, one variable was constructed to represent interaction between two illnesses ( $i$ and $j$ ) for use in cases where more than $20 \%$ of the respondents reported being sick from both illness $i$ and $j$. The interaction variable had a value of 1 if the person was sick from both illnesses and a value of 0 for any other outcome.
} 
TABLE 1. Mean values for life satisfaction (LS), domain satisfaction, and socio-demographic variables among representative national sample, by health condition, Costa Rica, 2004

\begin{tabular}{|c|c|c|c|c|c|c|}
\hline & $\begin{array}{l}\text { No illness }{ }^{a} \\
(\text { no. }=715)^{b}\end{array}$ & $\begin{array}{c}\text { Cancer } \\
(\text { no. = 15) }\end{array}$ & $\begin{array}{c}\text { Cardiovascular } \\
\text { disease } \\
\text { (no. = 102) }\end{array}$ & $\begin{array}{l}\text { Thyroid } \\
\text { disease } \\
\text { (no. = 38) }\end{array}$ & $\begin{array}{c}\text { Arthritis } \\
\text { (no. = 65) }\end{array}$ & $\begin{array}{c}\text { Infectious } \\
\text { disease } \\
\text { (no. = 127) }\end{array}$ \\
\hline LS & 5.28 & 5.60 & 4.98 & 5.24 & 4.97 & 5.09 \\
\hline \multicolumn{7}{|l|}{ Domain satisfaction } \\
\hline Health & 5.37 & 4.40 & 4.26 & 4.66 & 4.34 & 5.06 \\
\hline Economic & 4.80 & 4.00 & 4.25 & 4.26 & 3.66 & 4.52 \\
\hline Occupation ${ }^{c}$ & 5.07 & 4.73 & 4.81 & 4.92 & 4.62 & 4.63 \\
\hline Family & 5.51 & 5.30 & 5.38 & 5.24 & 5.54 & 5.47 \\
\hline Friendship & 5.28 & 5.60 & 5.30 & 5.63 & 5.11 & 5.29 \\
\hline Personal $^{d}$ & 4.79 & 4.73 & 4.74 & 4.79 & 4.74 & 4.69 \\
\hline Community services ${ }^{e}$ & 4.44 & 4.73 & 4.70 & 4.68 & 4.68 & 4.63 \\
\hline Income $^{f}$ & 579 & 309 & 494 & 485 & 356 & 537 \\
\hline $\mathrm{Age}^{\mathrm{g}}$ & 3.97 & 6.27 & 6.64 & 6.66 & 7.11 & 3.90 \\
\hline Gender (female $=1$ ) & 0.47 & 0.60 & 0.59 & 0.82 & 0.66 & 0.63 \\
\hline Education $^{h}$ & 3.61 & 2.93 & 3.05 & 3.13 & 2.83 & 3.35 \\
\hline $\begin{array}{l}\text { a "No illness" means the sur } \\
\text { have occurred among surv } \\
\text { b Number of observations. } \\
\text { c Main activity (e.g., job, don } \\
\text { d Availability of time to pursu } \\
\text { e Public services (e.g., trash } \\
\text { f Monthly household income } \\
\text { g Across } 10 \text { ordinal categori } \\
{ }^{\circ} \text { Across six ordinal categori }\end{array}$ & $\begin{array}{l}\text { ent did not repor } \\
\text { nts). } \\
\text { studies). } \\
\text { obbies and inter } \\
\text { ublic transport, r } \\
\text { s cardinal for sin } \\
\text { s cardinal for sin }\end{array}$ & $\begin{array}{l}\text { s well as recre } \\
\text { nditions, publi } \\
\text { of interpretati } \\
\text { of interpretati }\end{array}$ & $\begin{array}{l}\text { al and personal-dev } \\
\text { ing, neighborhood }\end{array}$ & ent activities. & out any othe & f illness that ma \\
\hline
\end{tabular}

latter), whereas only 10 percent were "extremely unsatisfied," "very unsatisfied," or "unsatisfied." This concurs with the general pattern found in most SWB studies $(17,38)$.

On average, when measured on a 1 to 7 scale, satisfaction was relatively high in the family (5.5), friendship (5.3), and health (5.2) life domains, and relatively low in the community services (4.5), economic (4.7), and personal (4.8) domains. Mean satisfaction in the occupation domain was 5.0 (versus a mean LS of 5.24).

In general, healthy people tend to report higher levels of LS than unhealthy people (e.g., people who suffer from cardiovascular and thyroid disease report, on average, lower LS than those without those diseases), with the exception of cancer patients (who have greater LS than healthy people ${ }^{8}$ ). Domains-of-life satisfaction is also, on average, lower for people who are ill versus healthy people, with the exception of friendship satisfaction and community services satisfaction.

Comparisons of mean satisfaction values from this study should be interpreted with care, however, as there were

\footnotetext{
The term "healthy people" refers to subjects who did not report any of the five illnesses under study. It should be noted, however, that no data were gathered about any additional types of illnesses (i.e., other than the five under study) that may have been suffered by respondents considered "healthy" under the study criteria.
}

important differences in mean sociodemographic and economic characteristics between the healthy and unhealthy groups.

\section{Socio-demographic/economic indicators}

Table 1 provides descriptive statistics for the main variables of the analysis (by health condition, including "no illness"). As shown in the table, unhealthy peoples' levels of satisfaction are relatively low not only in the health domain (as expected) but also in the economic and occupation domains.

Table 1 shows that, on average, healthy people have a much larger household income, ${ }^{9}$ are better educated, and are much younger than unhealthy people. There are also important differences in gender composition between healthy and unhealthy people.

Because socio-demographic and economic variables affect LS as well as satisfaction in various life domains, control variables for survey subjects' sociodemographic and economic indicators are recommended in any further study of WBI of illnesses. As described below,

\footnotetext{
9 Bidirectional causality may exist in regard to this variable (e.g., having higher household income implies a better state of health, and healthier people can attain greater incomes).
}

in this study, this issue was addressed through the use of multiple regression analyses.

\section{WBI of illnesses by life domain}

Regression analysis was used to study the relationship between satisfaction in each life domain and various sociodemographic, economic, and illness variables. The following specification was used to analyze satisfaction in each of the seven life domains studied: ${ }^{10}$

$$
\begin{aligned}
& D S_{i}^{k}=\beta_{0}^{k}+\beta_{1}^{k} A_{i}+\beta_{2}^{k} G_{i}+\beta_{3}^{k} E_{i} \\
& +\beta_{4}^{k} \ln \left(Y_{i}\right)+\beta_{5}^{k} \operatorname{Can}_{i}+\beta_{6}^{k} \operatorname{Card}_{i}+\beta_{7}^{k} \text { Thyr }_{i} \\
& +\beta_{8}^{k} A r t h_{i}+\beta_{9}^{k} I n f_{i}+\beta_{10}^{k} I_{i}^{\text {can, cand }} \\
& +\beta_{11}^{k} I_{i}^{\text {can, arth }}+\beta_{12}^{k} I_{i}^{\text {can, thyr }}+\beta_{13}^{k} I_{i}^{\text {card, arth }} \\
& +\beta_{14}^{k} I_{i}^{\text {card }, \text { thyr }}+\beta_{15}^{k} I_{i}^{\text {arth, thyr }} \\
& +\beta_{16}^{k} I_{i}^{a r t h, i n f}+\mu_{i}^{k} \\
& (k=1,2, \ldots, 7)
\end{aligned}
$$

where

$D S_{i}^{k}$ : Person $i^{\prime}$ s satisfaction in domain $k$ on a scale of 1 to 7

$A_{i}$ : $\quad$ Age of person $i$ (in ordinal groups of age)

\footnotetext{
10 Domains-of-life satisfaction is treated as a cardinal variable (justified by the above-mentioned finding that converting it from ordinal to cardinal did not have a substantial effect on the results)
} 
$G_{i}$ : Gender of person $i$ (0 if male; 1 if female)

$E_{i}$ : Education of person $i$ (in ordinal levels)

$\ln \left(Y_{i}\right)$ : Logarithm value of person $i$ 's household monthly income

$\mathrm{Can}_{i}$ : Cancer (a dichotomous variable with a value of 1 if person $i$ had any type of cancer disease during the last six months and 0 for any other outcome)

Card $_{i}$ : Cardiovascular disease (a dichotomous variable with a value of 1 if person $i$ had a cardiovascular disease during the last six months and 0 for any other outcome)

Thyr $r_{i}$ : Thyroid disease (a dichotomous variable with a value of 1 if person $i$ had a thyroid disease during the last six months and 0 for any other outcome)

$A r t h_{i}:$ Arthritis (a dichotomous variable with a value of 1 if person $i$ had arthritis during the last six months and 0 for any other outcome)

$\operatorname{Inf}_{i}: \quad$ Infectious disease (a dichotomous variable with a value of 1 if person $i$ had an infectious disease during the last six months and 0 for any other outcome)

$I_{i}^{\text {can,card: }}$ Cancer and cardiovascular disease (a dichotomous variable with a value of 1 if person $i$ had cancer and cardiovascular disease during the last six months and 0 for any other outcome)

$I_{i}^{\text {can,arth: }}$ Cancer and arthritis (a dichotomous variable with a value of 1 if person $i$ had cancer and arthritis during the last six months and 0 for any other outcome)

$I_{i}^{\text {can,thyr: }}$ Cancer and thyroid disease (a dichotomous variable with a value of 1 if person $i$ had cancer and thyroid disease during the last six months and 0 for any other outcome)

$I_{i}^{\text {card,arth: }}$ Cardiovascular disease and arthritis (a dichotomous variable with a value of 1 if person $i$ had cardiovascular disease and arthritis during the last six months and 0 for any other outcome)

$I_{i}^{\text {card,thyr: }}$ Cardiovascular and thyroid disease (a dichotomous variable with a value of 1 if person $i$ had cardiovascular and thy- roid disease during the last six months and 0 for any other outcome)

$I_{i}^{a r t h, t h y r:}$ Arthritis and thyroid disease (a dichotomous variable with a value of 1 if person $i$ had arthritis and thyroid disease during the last six months and 0 for any other outcome)

$I_{i}^{a r t h, i n f}$ Arthritis and infectious disease (a dichotomous variable with a value of 1 if person $i$ had arthritis and infectious disease during the last six months and 0 for any other outcome)

$\beta_{h}$ : Parameters to be estimated $(h=0$, ..., 16)

$\mu_{i}$ : Residual term for person $i$.

Table 2 shows the estimated coefficients for satisfaction in each life domain and the effect of various socio-demographic and economic variables, based on regression analyses. However, only the WBI of income and illness is reviewed here.

As shown in Table 2, income has a positive WBI in all life domains included in the study. This impact is statistically significant ( $p$-value $<0.05$ ) in all domains except "personal" and "community services." As expected, the WBI of income is relatively large in the economic domain (with a $172 \%$ increase in income reportedly increasing economic satisfaction by 0.69). ${ }^{11}$ The WBI of income in the occupation realm along with impact in the areas of family, health, and friendship, is also substantive (at $0.30,0.23,0.20$, and 0.18 , respectively). It should be noted that the health and friendship domains are very important for LS, as described in more detail below.

The study results indicated the WBI of the five categories of illnesses across the various life domains is not uniform. For example, cancer reportedly reduces health, economic, occupation, family, and community services satisfaction but increases friendship and personal satisfaction. Its WBI is strong in the health domain and substantive in the family and occupation domains.

Cardiovascular disease was reported to reduce satisfaction in all domains except "friendship," "personal," and "community services." Its WBI is strong in the area of health.

\footnotetext{
11 A change of one unit in logarithm of income corresponds to an increase of approximately $172 \%$ in raw income.
}

According to the study, thyroid disease reduces satisfaction in all domains of life except friendship. Its WBI is moderate in the family, economic, health, and occupation domains.

Arthritis reduces satisfaction in all domains except "family" and "personal" (and its impact is substantive and strong in the occupation and economic areas respectively).

Infectious diseases mainly reduce occupation and health satisfaction.

Table 2 also presents the square of the goodness-of-fit or correlation coefficient (the " $R$-squared" indicator) for the regressions, with and without the set of illness variables. Comparison of the two indicators allows for assessment of the marginal explanatory power of the illness variables. As shown in Table 2, the set of illness variables only has strong marginal explanatory power in the health domain.

As mentioned above, although the domains-of-life satisfaction responses were ordinal, it was determined that treating them as cardinal in the analysis did not substantially change the main study results. Therefore, for the sake of simplicity, these variables were treated as cardinal.

\section{Explanation of LS}

Domains-of-life approach. As mentioned above, the domains-of-life approach explains life satisfaction (LS) based on the levels of satisfaction in various life domains. Therefore, a general specification of LS would be:

$$
L S_{i}=f\left(\mathrm{Hea}_{i}, \mathrm{Eco}_{i}, \mathrm{Occ}_{i}, \text { Fam }_{i}, \text { Fri }_{i}, \text { Per }_{i}, \mathrm{Com}_{i}\right)
$$

where the variables are described as follows (on a 1-to-7 scale):

$L S_{i}$ : Person $i^{\prime}$ s life satisfaction $\mathrm{Hea}_{i}$ : Person $i$ 's health satisfaction $\mathrm{Eco}_{i}$ : Person i's economic satisfaction $\mathrm{Occ}_{i}$ : Person $i^{\prime}$ s occupation satisfaction $\mathrm{Fam}_{i}$ : Person $i$ 's family satisfaction $\mathrm{Fri}_{i}$ : Person $i^{\prime}$ s friendship satisfaction $\mathrm{Per}_{i}$ : Person $i$ 's personal satisfaction $\mathrm{Com}_{i}$ :Person $i$ 's community services satisfaction.

Consideration of personality traits. Domains-of-life satisfaction was modeled in terms of a set of explanatory variables (age, gender, education, income, and illness). However, domains-of-life 


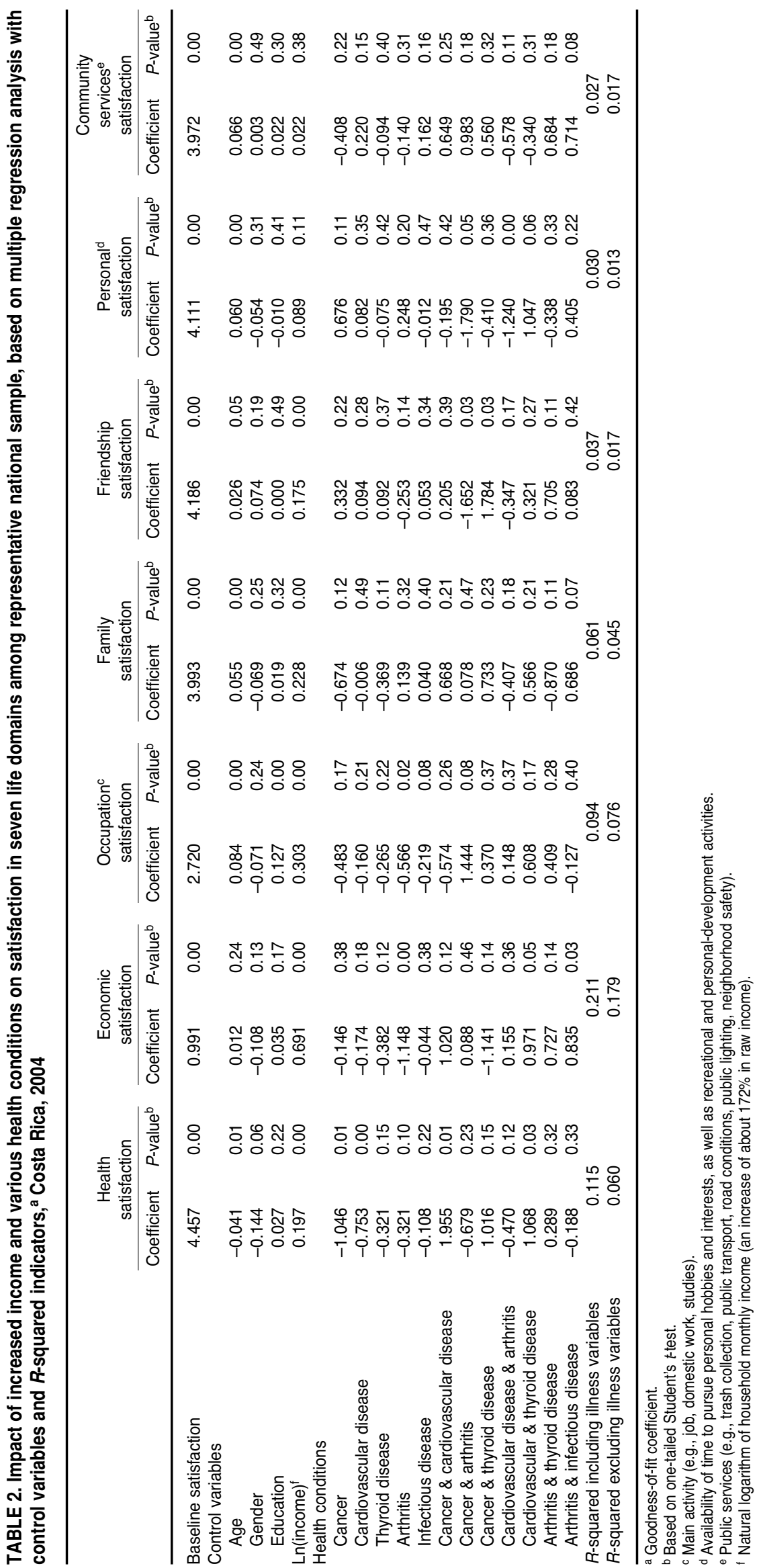


satisfaction could also be attributed to certain underlying factors (e.g., personality traits such as psychological characteristics or those related to socio-demographic, economic, and disease status). This scenario (the presence of underlying factors common to all levels of domains-of-life satisfaction) would imply an incorrect estimation of the relationship between life domains satisfaction and LS. Therefore, this study uses the methodology developed by van Praag and Ferrer-i-Carbonell (2), which calls for use of the residuals $\mu_{i}^{k}$ (see Equation 5) to estimate an underlying factor influencing satisfaction in all domains simultaneously. Factorial analysis with principal-components extraction was applied to residuals $\mu_{i}^{k}$, and a score regression technique was used to estimate a new explanatory variable called Trait.

The new Trait variable is introduced in Equation 7, which analyzes the relationship between LS and domains-of-life satisfaction (treating both as cardinal variables): ${ }^{12,13}$

$$
\begin{gathered}
\text { SS }_{i}=\alpha_{0}+\alpha_{1} \text { Hea }_{i}+\alpha_{2} \text { Eco }_{i}+\alpha_{3} \text { Occ }_{i} \\
+\alpha_{4} \text { Fam }_{i}+\alpha_{5} \text { Fri }_{i}+\alpha_{6} \text { Per }_{i}+\alpha_{7} \text { Com }_{i} \\
+\alpha_{8} \text { Trait }_{i}+\varepsilon_{i}
\end{gathered}
$$

where

$\varepsilon_{i}:=$ error term for person $i$ and

$\alpha_{j}$ : = the parameters to be estimated (with $j=0,1, \ldots, 8$ ).

Table 3 presents the estimated coefficients, their corresponding probabilities or $p$-values (based on a one-tailed Student's $t$-test), and the $R$-squared indicators.

As shown in Table 3, satisfaction in the health and family domains is critical for a person's satisfaction with life. A onestep increase in health is associated with almost one-third of a one-step increase in LS, and the same increase in family satisfaction is associated with a rise of about a quarter of one step in LS. ${ }^{14}$ In other words, LS is extremely affected by changes in satisfaction levels in the health and family domains. Satisfaction in the economic domain is also important for LS (but to a much lower degree than health and family satisfaction). Sat-

\footnotetext{
12 As mentioned above, econometric exercises (not shown in this report) indicate it is appropriate to handle the LS variable and the domains-of-life satisfaction variables as cardinal.

13 A linear specification is used for simplicity of interpretation.

14 LS is treated as a cardinal variable (with values ranging from 1 to 7 ); therefore, a one-step increase in LS implies a one-category jump.
}

\begin{tabular}{|c|c|c|c|c|c|}
\hline & Coefficient & $p$-value ${ }^{c}$ & $\begin{array}{c}\text { Standard } \\
\text { error }\end{array}$ & $\begin{array}{l}\text { Lower } \\
\text { bound }^{d}\end{array}$ & $\begin{array}{l}\text { Upper } \\
\text { bound }^{\text {d }}\end{array}$ \\
\hline Constant & 0.491 & 0.27 & 0.82 & -1.12 & 2.10 \\
\hline Health & 0.301 & 0.00 & 0.04 & 0.22 & 0.39 \\
\hline Economic & 0.163 & 0.00 & 0.04 & 0.09 & 0.24 \\
\hline Occupation $^{e}$ & 0.079 & 0.05 & 0.05 & -0.01 & 0.17 \\
\hline Family & 0.230 & 0.00 & 0.05 & 0.13 & 0.34 \\
\hline Friendship & 0.036 & 0.24 & 0.05 & -0.06 & 0.14 \\
\hline Personal $^{f}$ & 0.094 & 0.01 & 0.04 & 0.02 & 0.17 \\
\hline Community services ${ }^{g}$ & 0.037 & 0.13 & 0.03 & -0.03 & 0.10 \\
\hline \multicolumn{6}{|l|}{ Common variable } \\
\hline Traith $^{\text {h }}$ & 0.047 & 0.36 & 0.13 & -0.21 & 0.30 \\
\hline
\end{tabular}

TABLE 3. Life satisfaction (LS) ${ }^{\mathrm{a}}$ explained by satisfaction in various life domains among representative national sample, based on regression analysis, Costa Rica, 2004 ${ }^{\text {b }}$

a Dependent variable.

${ }^{\mathrm{b}}$ Goodness-of-fit coefficient ( $R$-squared indicator) $=0.418$.

c Based on one-tailed Student's $t$-test.

d $95 \%$ confidence interval.

e Main activity (e.g., job, domestic work, studies).

${ }^{f}$ Availability of time to pursue personal hobbies and interests, as well as recreational and personal-development activities. g Public services (e.g., trash collection, public transport, road conditions, public lighting, neighborhood safety).

$\mathrm{h}$ Common psychological characteristic influencing satisfaction in all life domains simultaneously.

isfaction in the personal and occupation domains is also relevant (and statistically significant). Community services satisfaction and friendship satisfaction have a very small positive impact on LS. The Trait variable is statistically nonsignificant (its main role is to allow for a good econometric specification, as shown in Equation 7). The $R$-squared indicator is 0.42 , which can be considered relatively high based on other studies analyzing the relationship between LS and domains-of-life satisfaction.

\section{Monetary valuation of illnesses}

Information from Tables 2 and 3 can be used to determine the impact of additional income and illness on various life domains and, consequently, satisfaction with life (LS). This information is required to estimate the monetary value of an illness (MVI) based on the general formulas shown in Equations 1-4. It should be noted that these equations are generic, and therefore the explicit specifications shown in Equations 5 and 7 must be considered for proper calculation of the impact of income and illness on LS and, in turn, the MVI.

Impact of increased income on LS. The second column in Table 4 is constructed from results presented in Tables 2 and 3. It shows how a $172 \%$ change in income affects LS and deconstructs this impact in terms of the various life domains. The impact of income $(Y)$ on LS is calculated using Equation 8:

$$
\frac{\partial L S}{\partial \ln (Y)}=\sum_{k=1}^{7} \frac{\partial D S_{k}}{\partial \ln (Y)} \frac{\partial L S}{\partial D S_{k}}
$$

For example, as shown in Table 2, a $172 \%$ increase in income increases economic satisfaction by 0.691 , whereas an increase of one satisfaction point in economic satisfaction leads to a rise of 0.163 in LS (Table 3). It is thus possible to conclude that a $172 \%$ increase in income implies a rise of 0.1126 in LS as a consequence of its WBI in the economic realm (Table 4). Repeating the exercise for all life domains allows for the calculation of the total impact of income on LS. Table 4 shows the domain-structure impact of illnesses on LS.

The second column in Table 4 shows that a large amount of the impact of income on LS occurs through the economic domain $(43 \%)$. The impact of income on LS through the health and family domains is also relatively large (22 and $20 \%$ of total impact, respectively). Income's impact through the occupation domain is small but not negligible.

When the impact in all life domains is taken into consideration, an increase of $172 \%$ in a person's household income raises his/her LS by 0.26 .

Impact of illnesses on LS. As shown in Table 2, the five types of illnesses can affect LS through many different life domains, and the structure of their impact in these different domains can vary widely. This impact (effect of illness $h$ on 
TABLE 4. Impact of $172 \%$ increase in income and five different health conditions on life satisfaction (LS) among representative national sample, by various life domains, Costa Rica, 2004

\begin{tabular}{|c|c|c|c|c|c|c|}
\hline & $\begin{array}{c}172 \% \\
\text { increase in } \\
\text { income }\end{array}$ & Cancer $^{a}$ & $\begin{array}{c}\text { Cardiovascular } \\
\text { disease }^{\mathrm{a}}\end{array}$ & $\begin{array}{l}\text { Thyroid } \\
\text { disease }^{\text {a }}\end{array}$ & Arthritis $^{a}$ & $\begin{array}{l}\text { Infectious } \\
\text { disease }^{\text {a }}\end{array}$ \\
\hline Health satisfaction & 0.0593 & -0.3148 & -0.2267 & -0.0966 & -0.0966 & -0.0325 \\
\hline Economic satisfaction & 0.1126 & -0.0238 & -0.0284 & -0.0623 & -0.1871 & -0.0072 \\
\hline Occupation $^{\mathrm{b}}$ satisfaction & 0.0239 & -0.0382 & -0.0126 & -0.0209 & -0.0447 & -0.0173 \\
\hline Family satisfaction & 0.0524 & -0.1550 & -0.0014 & -0.0849 & 0.0320 & 0.0092 \\
\hline Friendship satisfaction & 0.0063 & 0.0120 & 0.0034 & 0.0033 & -0.0091 & 0.0019 \\
\hline Personal ${ }^{\mathrm{C}}$ satisfaction & 0.0084 & 0.0635 & 0.0077 & -0.0071 & 0.0233 & -0.0011 \\
\hline Community services ${ }^{d}$ satisfaction & 0.0008 & -0.0151 & 0.0081 & -0.0035 & -0.0052 & 0.0060 \\
\hline LS & 0.2638 & -0.4714 & -0.2498 & -0.2719 & -0.2875 & -0.0410 \\
\hline
\end{tabular}

a Values are based on combined estimated coefficients shown in Tables 2 and 3 of the current study (regardless of their level of significance according to the Student's $t$-test).

${ }^{b}$ Main activity (e.g., job, domestic work, studies).

${ }^{c}$ Availability of time to pursue personal hobbies and interests, as well as recreational and personal-development activities.

d Public services (e.g., trash collection, public transport, road conditions, public lighting, neighborhood safety).

LS) can be calculated and deconstructed by domain, ${ }^{15}$ as shown in Equation 9:

$$
\frac{\partial L S}{\partial I l l n e s s_{h}}=\sum_{k=1}^{7} \frac{\partial D S_{k}}{\partial \text { Illness }_{h}} \frac{\partial L S}{\partial D S_{k}}
$$

Combined information from Tables 2 and 3 is used to calculate columns $3-7$ in Table 4, which show the impact of the five general illness categories on LS by life domain: ${ }^{16}$

1. Cancer. Cancer reduces LS by 0.47, with most of the decline taking place through the domain of health satisfaction (a fundamental domain for LS, as shown in Table 3). As shown in Table 2 , cancer reduces health satisfaction by 1.05. As shown in Table 3, a decrease of one point in health satisfaction reduces LS by 0.3. Furthermore, cancer has a significant negative WBI in the family domain, reducing family satisfaction (another crucial variable for LS) by 0.67 (Table 2). Thus, cancer has a strong impact on LS due to its strong effect in the domains of life important to the LS variable.

2. Cardiovascular disease. Cardiovascular disease reduces LS by 0.25 , with the

\footnotetext{
15 The analyses assume illness incidence is not correlated; therefore, interactions between illnesses are not taken into consideration.

16 Calculation of the MVI is based on all estimated coefficients in Tables 2 and 3 regardless of their level of significance according to the Student's $t$ test (based on the assumption that it is preferable to calculate MVI using its estimated coefficient than to assume the coefficient equals zero due to any relatively high $p$-values from the corresponding Student's $t$-test).
}

impact occurring mostly in the health domain (plus a small impact in the economic and occupation domains).

3. Thyroid disease. Thyroid disease reduces LS by 0.28 . This relatively large WBI occurs not only in the health domain but also in the family and economic areas. Its impact through occupation satisfaction is also relatively substantial.

4. Arthritis. The decline in LS due to arthritis is almost 0.29 , which is relatively large. The WBI takes place mostly through the economic and health domains. It is noteworthy that the impact of this disease through the economic domain is larger than that occurring through the health domain.

5. Infectious disease. Infectious disease has a small impact on LS (affecting mostly health and occupation satisfaction).

MVI. The estimated coefficients in Tables 2 and 3 can be used to calculate the percentage increase in income required to compensate for an illness so that LS remains unchanged. ${ }^{17}$ This percentage

\footnotetext{
17 The mathematical procedure consists of three steps: 1) using the specifications shown in Equations 5 and 7 to derive a complete explanation of LS in terms of the presence or absence of illnesses, the logarithm of income, and socio-demographic variables; 2) differentiating LS with respect to the logarithm of income and a specific illness $(h)$; and 3) estimating the increase in the logarithm of income that would be required to keep LS constant in the presence of illness $h$ by setting the change in LS to zero. The resulting mathematical computations allow for the calculation of the percentage change in raw income that is required to keep LS constant in the presence of illness $h$ (as shown in Equation 10).
}

change in income can be considered as the MVI calculated from a LS approach. Equation 10 shows how MVI is calculated for each different illness. ${ }^{18}$

$$
\begin{gathered}
M V I_{h, L S-\text { Approach }} \\
=\left(\frac{\Delta Y / Y}{\Delta D_{h}}\right)_{\Delta L S=0}=e^{-\frac{\partial / \partial \text { Illness }_{h}}{\partial L S / \partial \operatorname{In}(Y)}}-1
\end{gathered}
$$

Table 5 shows the monetary values of the five general categories of illnesses under study, using the LS approach. According to the study results, a person's income needs to be raised about 500\% to compensate for the negative WBI of cancer, while cardiovascular disease requires an income increase of about $160 \%$, thyroid disease and arthritis require an increase of about 200\% (180 and 197\%, respectively), and the compensation value for infectious disease is about $17 \%$.

For a resident of a household with average monthly household income equal to that of the study sample (about US\$ 540), an estimated monthly compensation of about US\$ 2695 would be necessary to keep his/her LS constant in the presence of cancer. The compensation would be about US\$ 859 in the presence of cardiovascular disease, about US\$ 972 for thyroid disease, about US\$ 1064 for arthritis, and about US\$ 92 for infectious disease.

An alternative interpretation of the figures presented in Table 5 that would underscore the importance of public health risk reduction policies is that the MVI represents the value of disease prevention and can therefore be used for comparing disease-prevention or healthpromotion policies with economicgrowth policies in terms of cost-benefit. As noted in the table, the duration of the illness should be taken into consideration when calculating total MVI.

\section{DISCUSSION}

Public-policy decisions that involve the use of scarce resources ultimately require trade-offs that are not easily re-

\footnotetext{
18 The current research focuses on the impact of a single illness on health and LS. Therefore, the case of having two illnesses simultaneously is not covered in this report (i.e., in the current monetary valuation it is assumed that illnesses emerge independently). However, some illnesses could have a joint probability distribution function.
} 
TABLE 5. Monetary value of five categories of illness as percent and absolute change in income required to maintain pre-illness level of life satisfaction among representative national sample, Costa Rica, 2004

\begin{tabular}{lcc}
\hline & \multicolumn{2}{c}{ Monetary value $^{\mathrm{a}}$} \\
\cline { 2 - 3 } & $\begin{array}{c}\text { Percent change } \\
\text { in income }\end{array}$ & $\begin{array}{c}\text { Absolute change } \\
\text { in income }\end{array}$ \\
\hline Cancer & 499 & 2694.60 \\
Cardiovascular disease & 159 & 858.60 \\
Thyroid disease & 180 & 972.00 \\
Arthritis & 197 & 1063.80 \\
Infectious disease & 17 & 91.80 \\
\hline a Monthly cost of illness. & & \\
b In U.S. dollars, based on average monthly household income of 250 000 Costa Rican colones \\
(about US\$ 540).
\end{tabular}

solved (particularly in cases where markets are not yet fully operational). The provision of health services, broadly understood to include prevention policies as well as remedial ones, is no exception to this problem (e.g., policy-makers must decide whether to allocate scarce resources to the prevention of one illness (i) versus another $(j))$. Thus, monetary valuation methodologies have emerged for assessing the value of alternative uses of scarce resources to help policy-makers make decisions that maximize social value. These decisions require an assessment of the value of each option, in monetary terms. Policy-makers may also face investment decisions (e.g., whether or not to build a health center) that require a cost-benefit analysis, with costs expressed in monetary terms and benefits (e.g., the reduction in the incidence of some illnesses) that require a monetary valuation to determine if the project will enhance well-being. In many cases, a monetary valuation is needed to determine appropriate compensation for a specific loss (e.g., persons' loss of health or physical capabilities).

This study applies the SWB valuation approach - an alternative to more widely used methodologies such as WTP and market-price valuation-to calculate the monetary value of different illnesses in Costa Rica. This approach assumes the MVI or monetary value of an illness equals the income compensation required to keep SWB constant despite the onset of the illness. In essence, this approach is closer to economic valuation theory, which asserts that the value of a good corresponds to the maximum amount of money a person is willing to exchange for that good without seeing a decline in his/her well-being or utility (and market prices are therefore equal to the monetary value of the goods). The difference between the SWB approach and the WTP or market-price valuation approaches arises not from the valuation criterion itself, but from the assumptions implicit in the valuation methodology. Hence, while the SWB valuation approach is based on experienced utility (based on Kahneman's definition of the term as the well-being that is experienced as a result of an actual event (12)), the WTP and market-price valuation approaches are based on decision utility (the well-being that is expected to be experienced as a result of a future or hypothetical event). Research studies by Kahneman et al., Loewenstein and Schkade, and Gilbert $(12,39-41)$ show that people have difficulty in predicting their experienced utility, often resulting in a lack of correlation between this type of judgment and the actual outcome. The SWB valuation approach may therefore be advantageous to the more traditional valuation approaches such as WTP and market-price valuation approaches, which require decision utility judgment and thus run the risk that survey respondents may make systematic mistakes in evaluating WBI (especially that resulting from hypothetical events such as having a certain type of illness that they have never experienced). In any event, it is clear that more research is needed on the implications of the use of alternate approaches for valuation and policy-making. The aim of this report is not to settle the debate but to foster further research to address it.

The current study used an LS conception of well-being and a domains-of-life approach to explain satisfaction in life. Hence, it focused on estimating various illnesses' monetary value in terms of LS and on mapping out their WBI in specific life domains.
The study data showed 1) how satisfaction in the different life domains is affected by five general categories of illness (cancer, arthritis, cardiovascular disease, thyroid disease, and infectious disease); 2) that illnesses differ in terms of their WBI in various life domains; and 3) that it is therefore possible to map out the WBI of both illness and income, based on the impact on a person's satisfaction in various life domains.

The study results indicate that LS is highly sensitive to satisfaction in the health and family domains (versus satisfaction in the economic domain, which is relevant, but less important), and satisfaction in the occupation and personal domains is not negligible (versus satisfaction levels in the friendship and community service domains, which have a very small WBI). Based on the global impact of illnesses and income on a person's LS, it was possible to estimate the MVIs (i.e., the income compensation required to keep a person's LS constant despite the onset of illness). Results indicated that income must rise about 500\% to compensate for cancer (which clearly has a high cost in terms of well-being), $160 \%$ for cardiovascular disease, $200 \%$ for arthritis and thyroid disease, and $17 \%$ for infectious disease.

The relatively large value of these estimates indicates the importance of developing effective disease-prevention and health-promotion policies to support well-being and that social policy should not be marginalized in favor of physical investments.

\section{Limitations}

There were some limitations in the study's empirical research that could be addressed in future research. Many of these arose from the specific nature of the database. For example, panel or longitudinal data would have been preferable to the cross-sectional type data used in this study for following up personal SWB. Data captured over time would be advantageous for this type of study not only because the impact of an illness can change throughout the different stages of the disease but also because the literature shows that people may adapt to higher income by adjusting their aspirations upward (hedonic adaptation in consumption). This type of habituation would imply the need for pro- 
gressively higher levels of income to compensate for the presence of the same type/level of illness over time. In addition, the database used for this study did not provide information about the severity, duration, or stage of the illness, and no information was collected about personal or social conditions, despite evidence that the impact of an illness on a person's LS is mediated by his/her personal context (e.g., access to a family network) and social context (e.g., access to a welfare regime in his/her country). As found by the current author in a past study, being ill and suffering from an illness are not always one and the same (42) (i.e., the impact of an illness can be mitigated by context variables).
Other limitations arose in the methodological area. For example, the specifications used to model the relationship between income, illnesses, and LS require additional empirical research. For example, further study is needed to ascertain the nature of the substitutability between income and illness (i.e., if, and to which degree, income can compensate for the loss of LS due to illness).

Additional research is also needed to better understand how income and illnesses affect satisfaction in different domains of life and what can be done to enhance the impact of income and to lessen the impact of illnesses. It would also be useful to study the impact of illnesses on satisfaction of family members.

\section{REFERENCES}

1. Ferrer-i-Carbonell A, van Praag B. The subjective costs of health losses due to chronic diseases: an alternative model for monetary appraisal. Health Econ. 2002;11(8):709-22.

2. van Praag B, Ferrer-i-Carbonell A. Happiness quantified: a satisfaction calculus approach. Oxford: Oxford University Press; 2004.

3. Drummond MF, O'Brien B, Stoddart GL, Torrance GW. Methods for the economic evaluation of health care programmes. 2nd ed. Oxford: Oxford University Press; 1997.

4. Diener A, O'Brien B, Gafni A. Health care contingent valuation studies: a review and classification of the literature. Health Econ. 1998; 7(4):313-26.

5. Cutler D, Richardson E. The value of health: 1970-1990. Am Econ Rev. 1998;88(2):97-100.

6. Culyer AJ, Newhouse JP, editors. Handbook of health economics. Amsterdam: Elsevier; 2000.

7. Ferrer-i-Carbonell A. Subjective questions to measure welfare and well-being: a survey. Amsterdam: Tinbergen Institute; 2002. (TI 2002-020/3).

8. Cummins RA. Comprehensive quality of life scale-adult: ComQol-A5 [manual]. 5th ed. Melbourne (Australia): School of Psychology, Deakin University; 1997.

9. Cummins RA. Directory of instruments to measure quality of life and cognate areas. 5th ed. Melbourne (Australia): School of Psychology, Deakin University; 1999.

10. Veenhoven R. The utility of happiness. Soc Indicators Res. 1988;20(4):333-54.

11. Argyle M. The psychology of happiness. 2nd ed. London: Routledge; 2001.

12. Kahneman D, Diener E, Schwarz N, editors. Well-being: the foundations of hedonic psychology. New York: Russell Sage Foundation; 1999.

13. Meadow HL, Mentzer JT, Rahtz DH, Sirgy G. A life satisfaction measure based on judgment theory. Soc Indicators Res. 1992;26(1):23-59.

14. Michalos A. Satisfaction and happiness. Soc Indicators Res. 1980;8(3):385-42.

15. Crooker KJ, Near JP. Happiness and satisfaction: measures of affect or cognition? Soc Indicators Res. 1998;44(2):195-224.
16. Tatarkiewicz W. Analysis of happiness. The Hague: Martinus Nijhoff; 1976.

17. Veenhoven R. Conditions of happiness. Dordrecht: Kluwer Academic; 1984.

18. Cummins RA. The domains of life satisfaction: an attempt to order chaos. Soc Indicators Res. 1996;38(3):303-32.

19. Salvatore N, Muñoz-Sastre MT. Appraisal of life: "area" versus "dimension" conceptualizations. Soc Indicators Res. 2001;53(3):229-55.

20. Veenhoven R. Developments in satisfaction research. Soc Indicators Res. 1996;37(1):1-46.

21. Rojas M. The complexity of well-being: a lifesatisfaction conception and a domains-of-life approach. In: Gough I, McGregor A, editors. Well-being in developing countries: from theory to research. Cambridge: Cambridge University Press; 2007.

22. Flanagan JC. A research approach to improving our quality of life. Am Psychologist. 1978; 33(2):138-47.

23. Headey B, Wearing A. Understanding happiness: a theory of subjective well-being. Melbourne (Australia): Longman Cheshire; 1992.

24. Andrews FM, Withey SB. Social indicators of well-being: Americans' perceptions of life quality. New York: Plenum Press; 1976.

25. Campbell A. The sense of well-being in America: recent patterns and trends. New York: McGraw-Hill; 1981.

26. Campbell A, Converse PE, Rogers WL. The quality of American life: perceptions, evaluations, and satisfactions. New York: Russell Sage Foundation; 1976.

27. Zapf W, Glatzer W. German social report: living conditions and subjective well-being, 1978-1984. Soc Indicators Res. 1987;19(1):1-171.

28. Clark AE, Oswald AJ. Unhappiness and unemployment. Econ J. 1994;104(424):648-59.

29. Di Tella R, MacCulloch R, Oswald AJ. Preferences over inflation and unemployment: evidence from surveys of happiness. Am Econ Rev. 2001;91(1):335-41.

30. Michalos AC, Zumbo BD. Health days, health satisfaction and satisfaction with the overall quality of life. Soc Indicators Res. 2002;59(3): 321-38.

\section{Conclusion}

This study shows that the SWB methodology provides useful information for personal valuation of illnesses. It also clarifies how this valuation emerges through a map of various life domains. Because this approach is based on survey subjects' experienced utility, it has advantages over alternative methods based on people's decision utility or stated preferences (e.g., contingent-valuation methods and discrete-choice analysis) and thus can be useful in designing health policies for disease prevention, resource allocation, and revenue-gathering strategies, and in evaluating the impact of social programs on well-being.
31. Michalos A, Zumbo B, Hubley A. Health and the quality of life. Soc Indicators Res. 2000; 51(3):245-86.

32. van Praag BMS, Frijters P, Ferrer-i-Carbonell A. The anatomy of subjective well-being. J Econ Behav Org. 2003;51(1):29-49.

33. van Praag BMS, Ferrer-i-Carbonell A. Agedifferentiated QALI losses. Discussion paper TI 02-105/3. Amsterdam: Tinbergen Institute; 2002.

34. Klose T. The contingent valuation method in health care. Health Policy. 1999;47(2):97-123.

35. Keely LC. Why isn't growth making us happier? Utility on the hedonic treadmill. J Econ Behav Org. 2005;57(3):333-55.

36. Stutzer A. The role of income aspirations in individual happiness. J Econ Behav Org. 2004; 54(1):89-109.

37. Ferrer-i-Carbonell A, Frijters P. How important is methodology for the estimates of determinants of happiness? Econ J. 2004;114(497): 641-59.

38. Veenhoven R. Happiness in nations: subjective appreciation of life in 56 nations, 19461992. Rotterdam: RISBO Press, Erasmus University; 1993.

39. Loewenstein G, Schkade D. Wouldn't it be nice? Predicting future feelings. In: Kahneman D, Diener E, Schwarz N, editors. Well-being: the foundations of hedonic psychology. New York: Russell Sage Foundation; 1999.

40. Kahneman D, Wakker P, Sarin, R. Back to Bentham? Explorations of experienced utility. Q J Econ. 1997;112(2):375-405.

41. Gilbert, D. Stumbling on happiness. Boston: Vintage; 2007.

42. Rojas M. Intra-household arrangements and health satisfaction: evidence from Mexico. Helsinki: United Nations University World Institute for Development Economics Research; 2004. (RP2008/57).

Manuscript received on 22 July 2008. Revised version accepted for publication on 15 March 2009. 
RESUMEN Objetivos. Explicar e ilustrar el uso del enfoque del bienestar subjetivo (BS) como metodología alternativa para evaluar la salud mediante la estimación del valor monetario de cinco categorías de enfermedades en Costa Rica y promover investigacio-

\section{Estimación del valor} monetario de las enfermedades en Costa Rica: enfoque del bienestar subjetivo nes comparativas sobre las ventajas y las limitaciones de enfoques alternativos para la valoración de la salud.

Métodos. Se utilizó el enfoque de valoración del BS para calcular el valor monetario de la enfermedad a partir de los datos empíricos de una encuesta representativa de Costa Rica realizada en 2004. El valor monetario se definió como el porcentaje estimado de los ingresos mensuales requeridos para compensar las pérdidas en satisfacción de vida - una noción primaria del BS - que ocurrirían una vez que comienza una enfermedad. Las cinco categorías generales de enfermedades estudiadas fueron: cáncer, enfermedad cardiovascular, enfermedad tiroidea, artritis y enfermedad infecciosa. Resultados. Se observó una amplia heterogeneidad en los valores monetarios de las diferentes enfermedades. Algunas enfermedades presentaron un valor monetario relativamente alto en relación con el ingreso medio de las personas, lo que indica el elevado valor de la buena salud y de los programas dirigidos a prevenir la emergencia de enfermedades o reducir su impacto negativo sobre el bienestar de las personas. Conclusiones. El enfoque de valoración del BS puede emplearse para estimar el valor monetario de las enfermedades y contribuir así al diseño de políticas de salud relacionadas con la asignación y la compensación de recursos y esquemas generadores de utilidades.

Palabras clave Política de salud; costo de enfermedad; satisfacción personal; felicidad; Costa Rica. 